\title{
Deficiência intelectual e linguagem escrita: discutindo a mediação pedagógica
}

\author{
Katia de Moura Graça Paixão* \\ Anna Augusta Sampaio de Oliveira**
}

\begin{abstract}
Resumo
O ensino da linguagem escrita em estudantes com deficiência intelectual é um tema que ainda carece de estudos acerca do papel do outro nesse processo, especialmente do professor. O objetivo do estudo foi investigar e analisar a mediação pedagógica a partir de uma pesquisa de intervenção envolvendo a linguagem escrita, direcionada a escolares com deficiência intelectual, a fim de discutir o papel do professor frente a este processo. Para responder esse objetivo, realizamos um estudo de caso envolvendo dois estudantes com deficiência intelectual matriculados nas séries iniciais do ensino fundamental e dois pesquisadores em contexto de intervenção. A análise das relações dialógicas estabelecidas entre os estudantes e pesquisadores em consonância aos resultados do desempenho dos estudantes nas áreas de linguagem, escrita, memória e leitura demonstraram contribuir para o planejamento pedagógico direcionado a esse público.

Palavras-chave: Deficiência Intelectual; Linguagem Escrita; Mediação Pedagógica.
\end{abstract}

\section{Intellectual disability and written language: discussing pedagogical mediation}

\begin{abstract}
The teaching of written language in students with intellectual disabilities is a subject that still lacks studies about the role of the other in this process, especially the teacher. In this study we present the results of an investigation on pedagogical mediation involving two students with intellectual disabilities enrolled in the initial grades of elementary education and two researchers in an intervention context. The analysis of the dialogic relations established between the students and researchers in line with the results of the students' performance in the areas of language, writing, memory and reading contribute to the pedagogical planning directed to this public.

Keywords: Intellectual Disability; Written language; Pedagogical Mediation.
\end{abstract}

\section{Introdução}

Historicamente, as abordagens em Educação Especial vêm se sustentando em uma visão determinista do desenvolvimento justificada pelas condições do sujeito com deficiência intelectual vistas como definitivas e limitantes, o que se traduz em práticas pedagógicas que minimizam o papel da educação sobre o curso desse desenvolvimento.

Como aponta Ferreira (1994), essa visão simplista sobre esse sujeito perpetua uma ação educativa que se caracteriza por ações massificadoras, generalizadas, repetitivas, pouco cooperativas e focadas em tarefas manuais, colocando-o em um status de eterna criança.

Nesse contexto, o aprendizado da linguagem escrita por estudantes com deficiência intelectual é apontado ainda como uma problemática, tanto em contextos especializados (escolas especiais) como inclusivos, conforme aponta levantamento bibliográfico em bases de dados nacionais e

*Endereço Eletrônico: kmgpaixao@ gmail.com

**Endereço Eletrônico: anna64.oliveira@gmail.com internacionais.

Em ambientes especializados, prepondera um ensino voltado à aquisição de tarefas básicas tais como alimentação, higiene, autocuidado e realização de tarefas manuais em detrimento dos conteúdos escolares. Em relação à escrita, observou-se que nessas instituições a escrita pouco está presente no trabalho educativo e que, quando apresentada, se resume a tarefas de cópia e repetição.

No contexto inclusivo, a realidade não é diferente. Apesar do aumento do número total de matrículas de estudantes com deficiência no Brasil a partir de 2008 (INEP/MEC, 2017), pesquisas desenvolvidas por Duarte (2008), Oliveira (2012), Silva (2015), Guebert (2013) e Mesquita (2015) apresentam dados alarmantes sobre a escolarização de pessoas com deficiência intelectual. Essas pesquisas apontam que, mesmo que grande parte das escolas pesquisadas dispusesse da figura do professor de educação especial, verificou-se que as concepções e a prática pedagógica na classe comum fundamentavam-se em uma visão de incapacidade desses sujeitos, inclusive sobre a aprendizagem da linguagem escrita. 
Apesar de a escrita estar disseminada em toda a sociedade, no interior das escolas, verificou-se que esses estudantes são excluídos dessas tarefas mesmo em situações de caráter coletivo, como elaboração de cartazes, textos coletivos, jogos, etc. Os professores imbuídos de uma visão preparatória e sequenciada para o aprendizado da escrita ofereciam tarefas descontextualizadas da turma em que o estudante estava inserido, com uso de palavras para ensino de fonemas específicos e com ênfase no treino motor da escrita.

Como podemos ver, em ambos os contextos, a escrita é apresentada enquanto ato motor e de difícil compreensão pelos estudantes com deficiência intelectual, o que justificaria a escolha por atividades que estivessem no nível de pensamento desses estudantes. Como bem aponta Vigotski (1998, p. 157), "[...] o que se deve fazer é ensinar às crianças a linguagem escrita, e não apenas a escrita das letras"

Com base na Teoria Histórico-Cultural, a escola deverá substituir as tarefas mecânicas, de exercício motor e de discriminação visual, privilegiando o desenvolvimento da linguagem em sua amplitude.

Estamos, sem dúvida, diante de um novo desafio: superar atividades repetitivas e desprovidas de sentido, para assumir uma nova e revolucionária postura frente à deficiência intelectual: possibilitar a constituição desses estudantes como sujeitos históricos, capazes de apreensão dos bens simbólicos e de desenvolvimento de seu pensamento [...].(OLIVEIRA, 2010, p. 345, grifo do autor)

Para o desenvolvimento do pensamento, deve-se, na escola, partir do abstrato ao concreto, do geral para o particular, uma vez que o conceito científico reflete os processos de transformação da relação universal em suas variadas formas, ou seja, em sua concretude. E isso também se aplica ao estudante com deficiência intelectual (EDI).

Tendo em vista que o conceito não é estático, pois a ciência se modifica o tempo todo, pensar teoricamente é pensar de formas diferentes, em momentos diversos da vida, a partir da experiência acumulada e da apropriação dos conceitos. A aprendizagem de um conceito proporciona uma compreensão mais elaborada sobre a própria vida da criança, de forma mais consciente [...] (PAIXÃO, 2018, p. 40)

Em se tratando de conceitos científicos, a aquisição da linguagem escrita traz uma grande mudança no curso do desenvolvimento psicológico, potencializando sua aprendizagem e a qualidade de suas relações sociais, por isso a importância de se discutir o cenário educacional brasileiro, especialmente sobre os resultados da escolarização da população brasileira.

Segundo dados obtidos por meio da Pesquisa Nacional por Amostra de Domicílios Contínua (PNADC), a quantidade de pessoas com 15 anos ou mais no Brasil que não sabem ler ou escrever é de 11.765 milhões, o que corresponde a uma taxa de analfabetismo de 7,2\% nessa faixa etária, sendo maior em pessoas com mais de 60 anos (IBGE, $2016^{1}$ ).

Esses dados nos instigam a pensar porque uma grande parcela da população brasileira não domina o funcionamento da linguagem escrita. E se é na escola, por sua função social, que se ensina a ler e escrever, como e o quê tem que ser ensinado para que um enorme contingente de crianças não aprenda a ler e escrever?

E em se tratando de estudantes com algum diferencial cognitivo, como aqueles com deficiência intelectual $^{2}$, esse processo não deveria ser desconsiderado ou considerado diferente; pelo contrário, por se tratar de uma condição específica que ocasiona algumas dificuldades não presentes em outros sujeitos, deve-se, mais ainda, enfatizar o significado das palavras e, além do mais, compreender o significado da escrita em uma visão muito mais abrangente e não apenas restrita à formalidade escolar.

Em classes comuns, a presença de estudantes com deficiência intelectual é uma conquista da escola brasileira e poderá nos permitir reconhecer a suas possibilidades de compartilhar experiências educacionais significativas capazes de destacar a dimensão constitutiva da escola para o desenvolvimento humano, por meio da construção de espaços colaborativos e acessíveis para a aprendizagem.

Como alguns estudos apontam, a exemplo de Braun (2012) e Pletsch (2010), os estudantes com deficiência intelectual também se apropriam da linguagem escrita, entretanto, é fundamental que se realize um investimento pedagógico intenso sobre os estes sujeitos, vislumbrando-se suas possibilidades e não suas fragilidades ou faltas.

Frente a esse cenário, impõe-se um grande desafio à produção científica e à escola: o da constituição da escrita naqueles com deficiência intelectual. Para isso, é fundamental a busca por novas perspectivas de ensino, a utilização de procedimentos didático-pedagógicos que permitam 
a apropriação da escrita, mesmo que com particularidades, daqueles com deficiência intelectual, a discussão de algumas diretrizes para evidenciar a ação do professor na direção da aprendizagem desses estudantes.

Preocupados com essa problemática, um grupo de pesquisadores brasileiros em parceria com uma universidade cubana desenvolveu entre $2013 \mathrm{e}$ 2016 o projeto: A questão da leitura e da escrita na área da deficiência intelectual: qual a melhor forma de ensino?, com apoio financeiro do CNPq, denominado aqui de Projeto de Alfabetização na Área da Deficiência Intelectual (PADI).

$O$ processo de intervenção foi realizado no ano de 2014 e trouxe dados riquíssimos para análise, resultando em diversos produtos científicos e outros ainda em produção.

O estudo apresentado neste artigo teve como objetivo investigar e analisar a mediação pedagógica a partir de uma pesquisa de intervenção envolvendo a linguagem escrita, direcionada a dois escolares com deficiência intelectual, a fim de discutir o papel do professor frente a esse processo. Ademais, tem como foco apresentar e discutir os dados relativos à mediação pedagógica empreendida nesse processo de intervenção, especificamente, do eixo relação dialógica, como também os resultados obtidos nas avaliações sobre o desempenho dos estudantes participantes a fim de buscar possíveis intersecções entre a mediação pedagógica e o desempenho nas áreas de leitura, escrita, memória e linguagem.

\section{A deficiência intelectual sob o olhar da Teoria Histórico-Cultural}

Muitos autores vêm se debruçando na compreensão dos postulados de Vigotski e suas implicações sobre o processo de aprendizagem e desenvolvimento das pessoas com deficiência, considerando que, a partir da Teoria HistóricoCultural, o desenvolvimento humano extrapola o biológico e as características físicas, pois " [...] o que decide o destino da personalidade, em última instância, não é o defeito em si, senão suas consequências sociais, sua realização sociopsicológica" (VIGOTSKI, 1998, p. 44).

A concepção de desenvolvimento e aprendizagem é radicalmente alterada por essa compreensão de Vigotski e seus colaboradores (LURIA, 1992; VIGOTSKI, 1991, 1995, 1997, 1998, 2009). Para ele, o aprendizado e o desenvolvimento estão inter-relacionados e combinados. Postula a necessidade de determinar pelo menos dois níveis de desenvolvimento: o nível de desenvolvimento real, isto é, o nível de desenvolvimento que corresponde ao conjunto de conhecimentos que a criança possui e as ações que realiza com autonomia, e às funções nas quais a criança já adquiriu em determinado momento; e o nível de desenvolvimento iminente, o que a criança é capaz de fazer com ajuda. Neste ponto cabe principalmente à escola um papel fundamental.

O processo de mediação em Vigotski é um conceito central para sua teoria, pois possibilita ao homem a apropriação da cultura, tendo em vista que o desenvolvimento cultural não se efetiva numa relação direta entre homem e a realidade, mas sim em uma relação mediada pelo outro, pelos signos e pelos meios simbólicos criados pela humanidade.

Segundo Sirgado (1991), é a mediação do outro que tem um sentido mais profundo no desenvolvimento cultural, sendo este a condição para o desenvolvimento, e não os objetos culturais.

Desse modo, ao pensarmos no processo educativo, o papel do outro enquanto mais qualificado, representando pelo professor, se devidamente organizado e intencional, leva os estudantes a níveis mais complexos de interação, comportamento e funcionamento intelectual que, por outras vias, seriam impossíveis de acontecer.

$\mathrm{O}$ conceito de mediação abre caminho para o desenvolvimento de uma abordagem não determinista do desenvolvimento, tendo em vista que os agentes mediadores servem como meios para que o sujeito também aja sobre os fatores sociais, culturais, psicológicos e biológicos. (PAIXÃO, 2018, p.43)

Portanto, cabe à escola criar as condições necessárias para o desenvolvimento do estudante $\mathrm{e}$ para a superação de seu próprio limite. Vygotsky e Luria (1996) demonstram que, "paralelamente às características negativas de uma criança defeituosa, ${ }^{3}$ é necessário também criar suas características positivas" (p.220).

O cerne do trabalho pedagógico não está, pois, na identificação de aspectos de não normalidade nos sujeitos com deficiência, uma vez que "[...] a pessoa com deficiência não tem algo 'a menos' que a normal [...]" (DE CARLO, 2001, p. 74), mas sim em reconhecer o que há de particular e peculiar nesses estudantes, sua forma de aprender e interagir e seus interesses. Não se trata de medir suas faltas, mas de considerar suas diferenças e investir nas relações sociais e na mediação pedagógica empreendida. 
Na mediação pedagógica, é o professor quem dirige e organiza esse processo com vistas à aprendizagem de conceitos, pois a criança não precisa aprender o que já é de seu domínio, mas aquilo que não conhece e, para isso, precisa do outro mais experiente, do mais capacitado, daquele que tenha domínio dos conceitos e compreenda o pensamento teórico que os fundamenta (PAIXÃO, 2018).

Entretanto, há que se considerar que na “[...] inter-relação entre sujeito (aluno) e o objeto de seu conhecimento (conteúdo escolar); nessa mediação, o saber do aluno é uma dimensão importante do seu processo de conhecimento (processo de ensinoaprendizagem)" (CAVALCANTI, 2005, p. 198199).

Para Vygotsky e Luria (1996, p. 221),

[...] ocorre a compensação do defeito. No correr da experiência, a criança aprende a compensar suas deficiências naturais; com base no comportamento natural e defeituoso, técnicas e habilidades culturais passam a existir, desestimulando e compensando o defeito. Elas tornam possível enfrentar uma tarefa inviável pelo uso de caminhos novos e diferentes. $\mathrm{O}$ comportamento cultural compensatório sobrepõe-se ao comportamento natural defeituoso.

A partir do mecanismo de compensação, que não está a cargo apenas da criança, a escola deve centrar sua atenção nas condições em que a aprendizagem se dá a fim de superar os limites oriundos da deficiência, de modo que sejam criadas formas alternativas para sua aprendizagem a partir das interações sociais e do acesso à cultura.

Enquanto sujeito histórico, o homem precisa estar inserido culturalmente no mundo e realizar ações com sentido que o colocam como participante de um grupo social, tais como utilizar gestos, palavras, atitudes, objetos, comportamentos apropriados na experiência e vivência ativa no mundo. Os atos possuem sentido histórico, não são naturais, são de natureza social, portanto apreendidos, apropriados na experiência humana.

Esta é a tarefa que a escola deverá desempenhar: levar os estudantes com deficiência intelectual à inserção cultural e significar suas atitudes, sua fala, seu desenho, suas produções, sua aprendizagem. Não se trata de ler e escrever: tratase do uso que se faz da leitura e da escrita, do sentido que é atribuído pelos estudantes com deficiência intelectual dessa prática social.

\section{Apresentando os caminhos metodológicos}

O projeto de cooperação mencionado anteriormente contou com a participação de três universidades brasileiras, na região sudeste do Brasil, com equipes de trabalho em cada localidade responsáveis pela organização, seleção da amostra de estudantes com deficiência intelectual e elaboração e aplicação dos instrumentos de coleta de dados, tais como: prontuário de educação especial dos estudantes, entrevista com as famílias dos estudantes selecionados, questionário com professores, registro dos dados de matrícula de cada estudante, diário de campo de visita escolar, registros de avaliação do PADI (inicial e processual), recortes das cenas significativas, tarefas realizadas por cada estudante no projeto e plano de intervenção semanal.

Este texto apresentará dados parciais relativos aos participantes de um dos locais de coleta, com foco nas interações sociais e no desempenho dos estudantes durante o decorrer da pesquisa. Da localidade selecionada, cabe esclarecer que participaram quatro estudantes com deficiência intelectual, entretanto, serão apresentados nesse momento os dados de apenas dois estudantes, que foram analisados na pesquisa de doutorado desenvolvida por uma das autoras do artigo.

A pesquisa foi desenvolvida durante um período de nove meses, em 2014, contabilizando 29 (vinte e nove) sessões de intervenção, e dos quais foram selecionadas cenas de três sessões ocorridas no início, meio e final do período de realização da pesquisa.

A cada sessão de intervenção, a equipe se debruçava sobre as interações envolvendo os estudantes e os pesquisadores para planejar a próxima sessão, a fim de prever materiais e recursos, selecionar e preparar atividades e definir estratégias para a próxima sessão de intervenção.

Semanalmente, era elaborado o Planejamento de Intervenção Semanal (PIS) pelo conjunto de pesquisadores envolvidos, assim como a produção dos recursos e materiais utilizados para estas sessões.

O PIS foi elaborado para possibilitar a organização do atendimento (produção de materiais, recursos, tarefas, sequência de atividades e definição de temáticas), para a reavaliação do planejamento, registro do desempenho dos estudantes e roteiro para posterior transcrição das filmagens de cada sessão.

Compunham o PIS os seguintes tópicos: conteúdos tais como linguagem oral, formação de palavras, leitura, ludicidade, coordenação motora 
fina, interpretação, sequência lógica e organização temporal, entre outros. Para cada conteúdo, eram propostos os objetivos específicos, que guiavam os procedimentos e direcionavam a avaliação do desempenho do estudante na atividade.

Os materiais construídos e as atividades propostas eram representativos de uma temática oriunda de uma brincadeira cantada, desenvolvida geralmente durante cerca de duas a três sessões. Por exemplo, na temática Rato, foi apresentado um travalíngua do rato ilustrado, depois foram propostas outras tarefas, tais como confecção de fantoches de palito dos personagens da parlenda, dramatização da parlenda, tarefa escrita de letras, palavras e associação de palavras, entre outras.

Neste artigo, apresentaremos algumas situações resultantes da pesquisa de intervenção obtidas por meio da transcrição de falas e ações entre pesquisadores e estudantes registradas em filmagens. Além disso, apresentaremos os dados de desempenho dos dois estudantes, registrados num Referencial de Avaliação e Acompanhamento, um instrumento de avaliação produzido pelo PADI com base no Referencial de Avaliação na Área da Deficiência Intelectual (RAADI) (SÃO PAULO, 2008).

Embora alguns autores apontem dúvidas sobre referenciais específicos para avaliação do desempenho dos estudantes com deficiência intelectual, no contexto da escola, como podemos observar pela afirmação de Symanski, Pellizzetti e Iacono (2009, p.110), “a avaliação desses alunos deveria estar submetida aos mesmos critérios dos demais?", a definição de critérios e a elaboração de indicadores podem se caracterizar como elementos facilitadores para o acompanhamento e avaliação da aprendizagem desses estudantes, além disso, qualquer que seja a situação a ser avaliada, não o fazemos sem referentes. Claro que é importante considerar, como nos aponta a própria Depersbiteris (2007, p.99), que "nenhum instrumento de avaliação é completo em si mesmo" e que a "diversidade de instrumento permite ao professor a obtenção de um número maior e mais variado de informações".

O Referencial de Avaliação e Acompanhamento elaborado pelo grupo de pesquisadores permitiu o registro dos dados do início ao final do estudo, e nos permitiu analisar condições relacionadas ao desenvolvimento cognitivo como percepção, coordenação motora, atenção, linguagem, simbolismos, representação gráfica, etc., e os níveis de realização, por meio do uso dos indicadores de realização da tarefa: satisfatória, parcial, com ajuda ou de não realização. Com base nos componentes qualitativos da avaliação pedagógica, construímos uma planilha para os registros gerais do desempenho dos estudantes, a qual foi sendo preenchida a cada mês e nos permitiu uma análise de antes e depois da intervenção. Posteriormente, os valores qualitativos foram transformados em valores numéricos com o objetivo de construir os gráficos que possibilitaram a análise do processo de desempenho dos estudantes. Os indicadores de aprendizagem, seus critérios e pontuação quantitativa estão sintetizados no quadro a seguir.

QUADRO 1 - Indicadores de avaliação dos estudantes durante as tarefas do PADI

\begin{tabular}{|c|c|c|c|}
\hline Indicador & Sigla & Critério de inclusão & Pontuação \\
\hline Realiza satisfatoriamente & RS & Realiza sem nenhum tipo de ajuda a tarefa & 3 \\
\hline Realiza parcialmente & RP & Realiza a tarefa ora com ajuda, ora com autonomia & 2 \\
\hline Realiza com ajuda & RA & Realiza com algum tipo de ajuda & 1 \\
\hline Não realiza & NR & Não consegue realizar de nenhuma forma a tarefa & 0,5 \\
\hline Não foi apresentado & NA & $\begin{array}{c}\text { Quando a competência avaliada não foi apresentada } \\
\text { na sessão de intervenção }\end{array}$ & 0 \\
\hline
\end{tabular}

Fonte: Elaboração própria com base nos dados de registro individual do PADI (2014)

À época, os estudantes aqui selecionados tinham 9 e 10 anos de idade, estavam matriculados em uma escola pública nos anos iniciais do ensino fundamental e possuíam diagnóstico de deficiência intelectual.
Neste estudo, apresentaremos dados resumidos sobre os estudantes, aqui denominados de José e Paulo, para situar o leitor no texto os quais apresentavam as seguintes características gerais: 
QUADRO 2 - Dados dos participantes da pesquisa

\begin{tabular}{|c|c|c|c|c|}
\hline Estudante & Data Nascimento & Idade na coleta & Gênero & Ano Escolar \\
\hline Paulo & $02 / 02 / 2005$ & 09 anos & Masculino & $2^{\circ}{ }^{\circ}$ ano E.F. \\
\hline José & $27 / 04 / 2004$ & 10 anos & Masculino & $3^{\circ}{ }^{\circ}$ ano E.F. \\
\hline
\end{tabular}

Fonte: Elaboração própria

\section{A mediação pedagógica e o aprendizado da linguagem escrita: discutindo os dados da pesquisa}

Sendo a relação do homem com o mundo mediada por outros homens, com intermédio dos signos e objetos culturais, é condição sine qua non para o desenvolvimento humano que a escola proporcione o acesso e apropriação dos mediadores culturais, tais como o cálculo e a escrita, e que considere as características e necessidades do sujeito em processo de aprendizagem. Desse modo, pensar sobre a aprendizagem é pensar também sobre o processo de ensino, pois como aponta Vigotski, sem aprendizagem, não ocorre o desenvolvimento, portanto, é preciso realizar um ensino desenvolvimental (DAVIDOV, 1988), ou seja, aquele que impulsiona o desenvolvimento.

Preocupados com a análise das mediações empreendidas durante os momentos de interação entre estudantes e pesquisadores ${ }^{4}$, analisamos diferentes cenas, transcritas de modo a apresentar detalhes observáveis, com foco nas interações sociais, nos gestos, linguagem, instrumentos e nos conteúdos de aprendizagem envolvidos no processo de mediação pedagógica, tendo em vista que definimos como eixos da análise da mediação pedagógica: relações dialógicas, os conceitos científicos e as ferramentas.

Para que a análise pudesse ser construída a partir de dados reveladores sobre as unidades que constituem a mediação pedagógica, apresentaremos neste texto o eixo relações dialógicas, tendo em vista que as falas dos participantes nos forneceram elementos centrais para o estudo da mediação pedagógica.

Contexto inicial: Após os estudantes assistirem e cantarem com auxílio do computador animação da música: Caranguejo, Kely solicitou que continuassem cantando a música, na sequência do trecho pausado.

Kely: Agora, eu vou falar uma parte da música e vocês vão falar a parte da música que vem depois. Caranguejo não é...

José: Pexe

Kely: Caranguejo...

Danilo: Como é Paulo? [chama a atenção de
Paulo]

Paulo: Pexe...

Aline: Pexe é. Caranguejo só é...

José: Pexe.

Kely: Peixe na enchente da...

José: Maré.

Kely: Agora palma, palma,...

José: Palma.

Kely: Agora, pé, pé, pé. Agora roda, roda, roda, Caranguejo...

Paulo: Pexe é. (Diário de Campo).

Nesta cena, a evocação das palavras é realizada a partir de estímulo oral após os estudantes terem cantado a música com auxílio de animações projetadas no computador. No momento de acompanhamento da música, os estudantes tiveram o auxílio das imagens, o que direcionou a atenção dos estudantes.

Essa estratégia inicial possibilitou aos sujeitos a identificação e compreensão de palavras contidas na música, o ritmo e a sequência da letra. Além disso, quando associadas às imagens da animação, as palavras orais apresentaram a linguagem oral como uma referência para o próprio objeto, ou seja, como seu substitutivo assim como a escrita deve se tornar, posteriormente, um meio auxiliar do pensamento.

Como aponta Vigotski (2009), a palavra é a unidade da linguagem e do pensamento, portanto, o ensino da linguagem escrita deve partir da palavra a fim de que o estudante se baseie no significado da palavra para compreender os elementos que a constituem. É importante destacar que Vigotski, ao tratar da linguagem escrita, o faz considerando toda a complexidade da organização do discurso interior, da fala interiorizada pela criança e que é expressa na ação. Portanto, a mediação pela linguagem do outro se caracteriza como uma intenção reguladora que possibilita ao sujeito, diante da emergência do discurso público, o processo de reflexão, análise e generalização por meio da interfuncionalidade das funções psicológicas humanas, logo, não há como sintetizar toda essa complexidade na ideia de competência ou habilidade, uma vez que todo o sistema neural está envolvido na relação de ensino, desenvolvimento e aprendizagem. Logo, ser 
competente e apresentar um desempenho superior depende em grande medida da mediação, no caso, a pedagógica, como disparadora para o desenvolvimento que está em iminência.

Nesta cena, estão presentes alguns elementos centrais durante a intervenção empreendida, tais como a palavra enquanto unidade no planejamento pedagógico e a necessidade de direcionamento da atenção dos estudantes para os elementos essenciais das tarefas, tendo em vista que a tomada de consciência é fundamental para o processo de apropriação dos conceitos e, inicialmente, é preciso que haja uma ação guiada pelo outro mais experiente, por quem domina esse signo, no caso da escola, o professor.

Entretanto, posteriormente, para a evocação dos trechos, os pesquisadores requisitaram que os estudantes buscassem a informação a partir de uma lembrança auditiva, sem suporte visual.

Esse também é outro aspecto fundamental no processo de desenvolvimento cultural do estudante com deficiência intelectual, pois como já problematizamos aqui, muito se fala sobre se fala sobre recursos para o ensino de estudantes com deficiência, mas pouco se trata da questão da mediação pedagógica.

Durante a pesquisa, foram construídos diversos recursos diferenciados (como a animação apresentada) para o ensino da linguagem escrita que se mostraram necessários especialmente nos momentos de registro escrito. Todavia, a exigência de resposta da tarefa proposta não pode se prender à percepção de elementos observáveis nos recursos, mas o recurso deve estar a serviço do estudante para compreender a tarefa proposta em situações mais difíceis, com vistas à superação do uso do material concreto.

Aos poucos, a oralidade, deve ser superada pelo emprego da escrita consciente, com a modificação da pergunta sobre como se fala para como se escreve.

Com vistas ao desenvolvimento da linguagem escrita e da compreensão de seu funcionamento, foi proposta a seguinte tarefa:

Contexto Inicial: Após cantarem a música: Caranguejo, foi entregue a letra da música para que circulassem algumas palavras determinadas pela pesquisadora e depois verificassem a quantidade de palavras encontradas.

Kely: Caranguejo. Onde está escrito caranguejo?

[Paulo mostra].

Kely: Até onde vai a palavra caranguejo?

[Paulo pega o lápis e risca a palavra, passando da limitação da mesma.

Kely intervém e mostra até onde vai a palavra na folha.

Paulo procura mais uma palavra].

Kely: Até onde vai? Qual é a letra que termina? [mostra a palavra que grifaram anteriormente, que era a mesma-caranguejo.

Kely retira o lápis de cor de Paulo para que ele olhe na folha].

Kely: Você está prestando atenção?

Paulo: Tô.

Kely: Com que letra começa caranguejo?

Paulo: $C$.

Kely: E termina com que letra? [aponta a letra na folha]

Paulo: $O$.

Num primeiro momento, Kely solicita que Paulo grife a palavra caranguejo no texto. Paulo não consegue grifar a palavra até o seu limite. Kely então muda a estratégia, tendo em vista que o objetivo anterior aparentemente não foi alcançado, ou seja, identificar e grifar a palavra caranguejo.

Analisando a tarefa, podemos analisar que essa tarefa pode trazer um resultado que não corresponde necessariamente ao que Paulo domina ou não. Primeiro, Paulo tem uma dificuldade motora considerável, e o manuseio do lápis dentro de um limite é para ele um tanto difícil. Além disso, quando executa a tarefa, seu foco está mais na execução do movimento do que na identificação da palavra.

A nova solicitação exige de Paulo a atenção aos caracteres que compõem a palavra em questão e trazem elementos para a pesquisadora que lhe possibilitam avaliar os conhecimentos que possui sobre a escrita, tais como identificação de letras, segmentação e leitura de palavras, diferentemente da estratégia anterior.

Quando organizada e planejada a partir das particularidades do estudante, a mediação pedagógica possibilita que o estudante avance em relação às suas hipóteses iniciais.

Entretanto, em alguns momentos de ensino, cabe também ao professor dizer ao estudante com deficiência intelectual aquilo que ainda não sabe ou possibilitar o acesso a ferramentas para compreensão sobre o funcionamento da escrita. Não é justo que se espere do estudante todas as respostas, deixando-o à deriva no processo de apropriação do conhecimento. Abandonado à própria sorte, o estudante com deficiência pouco avançará em seu processo de escolarização.

$\mathrm{Na}$ cena abaixo, Kely chama a atenção de José para as partes da palavra FACA, de modo que perceba qual a parte que falta e, ao mesmo tempo, 
Danilo também intervém para que Paulo participe na realização da tarefa. Primeiramente, a tarefa é discutida oralmente, de forma coletiva, para que depois cada um registre a tarefa. Durante a cena, Paulo não foca na folha apresentada, entretanto, a todo momento os pesquisadores insistem na sua participação. Ao orientarem sua percepção para uma finalidade específica na tarefa (formação da sílaba), Paulo presta atenção e emite uma resposta correta, como podemos constatar a seguir:

Kely: $O$ que falta aqui? [Dirige-se a José, apontando para a palavra faca, sem pronunciar a palavra]

José: $f a(. .) c$.$a .$

Danilo: $O$ que falta?

José: $c a$. [e registra apenas a letra $\mathrm{C}$ ].

Kely: Para ficar CA Paulo, depois da letra Co que precisa?

Paulo: A. (Diário de Campo).

Ao longo do processo de intervenção, pudemos constatar que a atenção se desenvolveu, tendo em vista que, por meio da atenção, "[...] a percepção se torna consciente, compreendendo, pois, a seleção de dados estímulos, a inibição de seus concorrentes e a retenção da imagem selecionada na consciência" (MARTINS, 2015, p. 143). O desenvolvimento das funções psíquicas superiores, tais como o comportamento voluntário, a atenção deliberada e a percepção é fundamental para a apropriação dos conteúdos escolares e, estes, por sua vez, possibilitam também uma modificação nas estruturas do pensamento. Desse modo, esses elementos também são parte integrante do currículo escolar e dizem respeito ao trabalho pedagógico nas escolas, especialmente no ensino de estudantes com deficiência intelectual.

A atenção, $[\ldots]$ se torna cada vez mais deliberada e arbitrária a partir do desenvolvimento do intelecto, isso significa que quanto mais o estudante tem acesso ao conhecimento, à cultura, mais se desenvolve a atenção [...]. (PAIXÃO, 2018, p. 123)

A fim de variar as estratégias de ensino, em diversos momentos utilizamos o jogo boliche com letras. Em cada garrafa foi colocada uma letra que, após ser derrubada, o estudante dizia uma palavra que iniciasse com a mesma

Contexto inicial: Paulo derruba uma garrafa com a letra $\mathrm{R}$.

Kely: Qual palavra começa com R?

Paulo: Pexe

Kely: Que letra é essa aqui? [mostrou-se a palavra peixe].

Paulo: P. (Diário de Campo)

Inicialmente, Paulo não diz uma palavra que se inicia com aquele som (R), porém, quando lhe é apresentada a palavra "peixe", ele identifica a letra inicial P. Durante o período de intervenção, não era apresentado aos estudantes as letras isoladas do alfabeto para que identificassem apenas, pois esse trabalho já era feito em sua alfabetização e ele já dominava, como pudemos analisar na cena acima.

A questão crucial aqui não está na identificação das letras. Apesar de Paulo identificar a letra isoladamente, a letra não era ainda para ele uma forma acessível de representação da oralidade.

Isso aponta a necessidade de uma mediação que não se limita aos conhecimentos que o estudante já possui; é preciso ampliar sua zona de desenvolvimento iminente. Nesta direção, a criação de novos motivos e interesses no fazer pedagógico é crucial para o desenvolvimento cultural do estudante.

Em uma dessas situações, durante a intervenção Paulo se interessa por livros de literatura infantil e contagia inclusive José:

Contexto Inicial: Momento de entrega da tarefa semanal, ao final da sessão de intervenção.

Paulo: Tem 'livo'? Velho?

Kely: Vou ver, tá bom?

[Paulo faz sinal de sim com a cabeça].

[Kely pega alguns livros que já haviam sido trabalhados com os estudantes e leva até a mesa, segurando com a mão].

José: Tem outro?

Kely: Eu vou emprestar o livro.

[José tenta pegar o livro da mão de Kely].

Kely: Calma, calma.

(...)

[Paulo sorri feliz com o livro]. (Diário de campo)

As situações aqui apresentadas representam sinteticamente a dinâmica das relações que se estabeleceram durante o processo de intervenção e embasam algumas conclusões a que chegamos sobre a mediação pedagógica em direção à apropriação da linguagem escrita, que foram também pautadas nos dados coletados sobre o desempenho dos estudantes neste período.

Com base nos dados de desempenho nas áreas de leitura, escrita, memória e linguagem, pudemos observar as condições de aprendizagem dos estudantes com deficiência intelectual inicialmente, durante e ao final da pesquisa, de modo a perceber seu percurso individual.

Todavia, além desses dados foi preciso apresentar as intervenções realizadas pelos 
pesquisadores envolvidos, pois entendemos que esse processo se deu de forma dialógica e compartilhada, como também todo e qualquer resultado relativo ao desempenho dos estudantes não pode ser interpretado de forma individual, ou seja, como resultado apenas da ação do estudante.

Os dados sobre o desempenho dos estudantes foram obtidos a partir do registro de avaliação do PADI, nos quais eram apresentados alguns descritores baseados nos conteúdos e nas funções psicológicas envolvidas no processo de alfabetização, tais como leitura de frases e palavras, escrita de palavras, compreensão de ordens simples e complexas, narração de fatos e memória imediata e de longo prazo, entre outros.

A seguir, apresentaremos o resultado da avaliação inicial e final dos estudantes ao longo do processo de intervenção:

GRÁFICO 1 - Avaliação inicial e final geral dos estudantes participantes da pesquisa

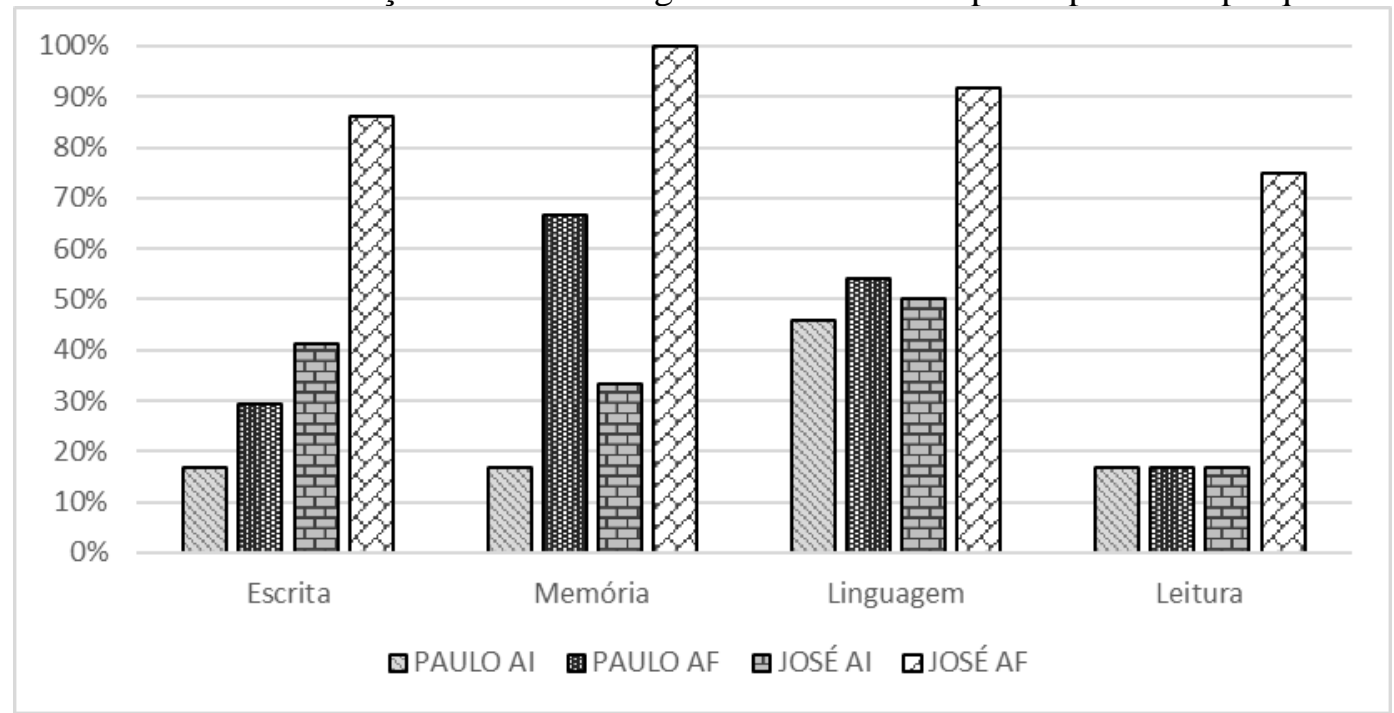

Fonte: Elaboração própria

Ao analisar o desempenho de Paulo e José na avaliação inicial (AI) e na avaliação final (AF), verificamos que Paulo teve um percentual de desenvolvimento geral diferente de José, pois em três das quatro áreas, escrita, memória e linguagem, ele apresentou desempenho abaixo de $30 \%$.

Apesar de inicialmente Paulo ter apresentado um desempenho elementar em comparação a José, ao final do processo de intervenção pudemos verificar que houve um avanço qualitativo em três das quatro áreas. Como destaque, temos o desenvolvimento da memória que, inicialmente, encontrava-se como $17 \%$ não realizado e, ao final, chegou ao patamar de $67 \%$ de realização ao contar com ajuda na execução das tarefas nessas áreas.

$\mathrm{Na}$ área da leitura, Paulo e José encontravamse no mesmo nível inicialmente (17\%), porém, José chega a $75 \%$ de desempenho nessa área.

Conforme apresentado no Gráfico 1, o desempenho geral de Paulo e José não se iguala após a intervenção, e isso não significa uma desvantagem entre eles; ao contrário: ambos tiveram avanços significativos. O desempenho de cada um é resultado de suas singularidades e dos sentidos estabelecidos entre os conceitos e as relações dialógicas.

Apesar de observarmos um ponto de partida semelhante na área da leitura entre os dois estudantes, o resultado após o processo de intervenção diferencia-se bastante. $\mathrm{O}$ ponto inicial não é definidor do desempenho final.

É importante esclarecer que partimos da ideia de que a avaliação do desenvolvimento não se dá de forma pontual, mas sim processual, em um contexto de observação constante do pesquisador, no qual se consideravam as falas, os registros e ações de cada estudante.

O desenvolvimento de cada sujeito, portanto, não está definido nas funções psicológicas já amadurecidas e avaliadas inicialmente, tampouco as ações dos pesquisadores poderiam se pautar nas limitações de cada estudante, e sim em suas possibilidades. Caso contrário, não seria possível 
observar o grande salto de aprendizado de José na área da leitura que, de um patamar de $17 \%$, projetase para $75 \%$ a partir dos critérios estabelecidos.

$\mathrm{Se}$ pautados em uma visão pedagógica tradicional, de prontidão para a alfabetização, esses dados poderiam ser impeditivos para o oferecimento de tarefas para além de suas capacidades atuais, tendo em vista que considerariam, por exemplo, que para se alfabetizar é necessário o domínio de prérequisitos, tais como identificação de vogais do alfabeto para o aprendizado das letras consoantes.

A fim de relacionar o desempenho às questões de mediação, apresentamos dados do desempenho específicos da escrita dos estudantes, nos quais para cada nível de aprendizagem foi atribuído um atributo qualitativo atrelado a um valor numérico a fim de perceber o processo de desenvolvimento de cada estudante.

Em relação aos dados de escrita, cabe dizer que são resultado da análise de tarefas desenvolvidas durante o processo de intervenção. No caso dos itens relativos à monossílaba, dissílaba, trissílaba, polissílaba e frase, foi solicitado aos estudantes que escrevesses palavras com essa quantidade de sílabas, sem a preocupação com a ordem em que seriam escritas, além da escrita de frases diversas

GRÁFICO 2 - Avaliação inicial e final da escrita dos estudantes participantes

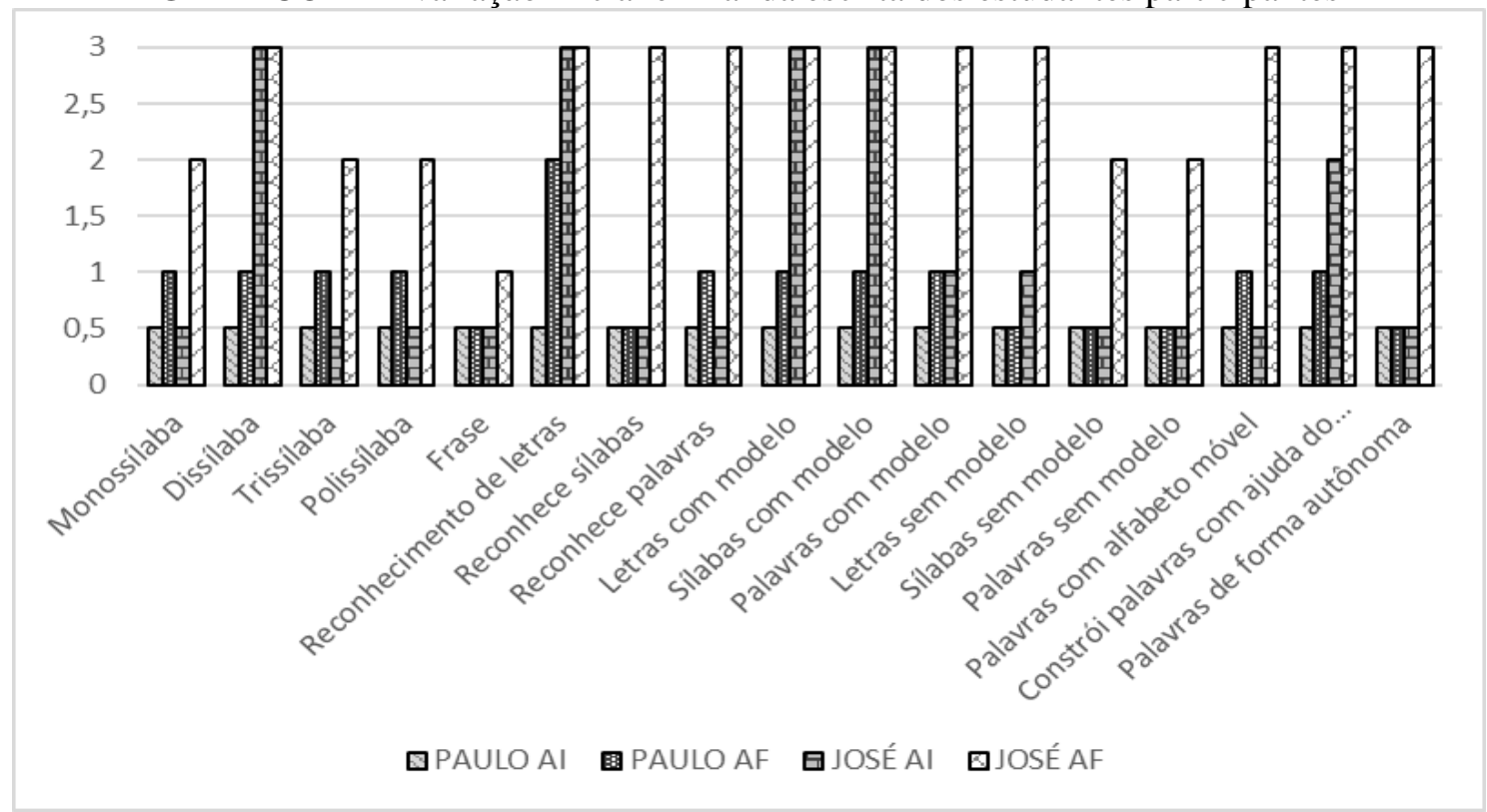

Fonte: Elaboração própria

No caso da escrita, observa-se que dos 17 critérios analisados, Paulo, ao final da pesquisa, não obteve nenhum desempenho satisfatório, enquanto José teve um total de 10 itens, porém, não podemos pautar seu desenvolvimento apenas nos dados finais. É preciso olhar todo o processo. Se destacarmos os dados iniciais sobre o descritor não realizava, observa-se que enquanto Paulo tinha o total de 17 itens, José tinha uma quantidade menor, com 10 itens. Portanto, mesmo não realizando satisfatoriamente nenhum dos descritores, Paulo apresentou um avanço ao realizar 11 itens com ajuda comparando-se aos 17 descritores sem realização inicial.

Para além das questões de conteúdo escolar, faz-se fundamental observar o desenvolvimento cultural e psíquico desses sujeitos, pois como aponta Vigotski (1998), o uso de signos conduz os seres humanos a uma nova estrutura de comportamento, que supera o limite do biológico e cria novas formas de funcionamento psicológico com base em seu desenvolvimento cultural, como pudemos evidenciar no desenvolvimento da memória ao final do processo de intervenção (Gráfico 1).

\section{Considerações}

Os dados gerais de avaliação confirmam o que as cenas trazidas anteriormente já demonstraram. Houve um desempenho ascendente dos dois sujeitos 
pesquisados, o que nos traz elementos para confirmar a tese de Vigotski (1995) de que a aprendizagem guia e promove os processos de desenvolvimento, e de que quanto mais o estudante com deficiência intelectual realiza tarefas com ajuda, mais terá potencializada sua aprendizagem, possibilitando-lhe posteriormente realizar essas mesmas tarefas com mais autonomia.

Os resultados da avaliação confirmam que as funções psicológicas não atuam em separado, ao contrário, combinam-se entre si, relacionam-se umas com as outras, por meio de "vínculos interfuncionais", como afirma Vigotski (1995). Desse modo, é importante frisar que não há desenvolvimento de uma função em contraposição a outra, ou seja, não há desenvolvimento da memória sem o desenvolvimento da percepção e da atenção, por exemplo. Esses processos não ocorrem em separado: são interdependentes e concomitantes.

Um mundo de oportunidades de desenvolvimento cultural e, portanto, psíquico, se abre ao estudante a partir da aprendizagem da linguagem escrita. Entretanto, o ambiente escolar há de ser ainda mais atraente e problematizador. É necessário que o aprendizado ocorra de maneira a instigar o indivíduo pela busca de conhecimento e pela prática da leitura e da escrita enquanto formas de compreensão e expressão do mundo.

Como pudemos observar nesta pesquisa, as mediações pedagógicas empreendidas evidenciaram que a busca pelo desenvolvimento da linguagem escrita nos escolares com deficiência intelectual possibilitou a ampliação da zona de desenvolvimento iminente $^{5}$ nesses sujeitos, pois lhes exigiu novas formas de pensamento e o uso consciente de processos psicológicos superiores, tais como a percepção, a atenção, a linguagem, o comportamento voluntário e a memória.

Isso aponta que, "[...] a criança orientada, ajudada e em colaboração sempre pode fazer mais e resolver tarefas mais difíceis do que quando sozinha" (VIGOTSKI, 2009, p. 328). E ainda que, a partir do encontro e relação com o outro, abrem-se novas oportunidades de aprendizagem tanto para o estudante quanto para o professor.

\section{Notas}

1 Dados disponíveis no site do IBGE: <https://www.ibge.gov.br/estatisticasnovoportal/sociais/educacao/17270-pnadcontinua.html? edicao $=18971 \& \mathrm{t}=$ resultados $>$. Acesso em: 4 jul. 2017.
2 Termo utilizado em substituição a "deficiência mental", aprovado na Declaração de Montreal sobre Deficiência Intelectual em 2004, e conforme recomendação da International Association for the Scientific of Intellectual Disabilities (IASSID) Associação Internacional de Estudos Científicos das Deficiências Intelectuais, em 2007.

3 Mantivemos a expressão original de Vigotski, cujo significado pode ser entendido como "criança com deficiência".

4 Os pesquisadores envolvidos diretamente na intervenção foram denominados como Kely, Danilo e Aline (esta participou como assistente de filmagem em um dos encontros).

5 Utilizamos a terminologia sugerida por Prestes (2010), quanto a tradução do termo zona blijaichego razvitia, presente nas obras em russo de Vigotski.

\section{Referências}

BRAUN, P. Uma intervenção colaborativa sobre os processos de ensino e aprendizagem do aluno com deficiência intelectual. 2012. 324f. Tese (Doutorado em Educação) - Universidade do Estado do Rio de Janeiro, Rio de Janeiro, 2012.

CAVALCANTI, L. S. Cotidiano, mediação pedagógica e formação de conceitos: uma contribuição de Vygotsky ao ensino de geografia. Cad. Cedes, Campinas, vol. 25, n. 65, p.185-207, maio/ago, 2005.

\section{DAVIDOV, V.V. Problemas do Ensino}

Desenvolvimental: a experiência da pesquisa teórica e experimental na psicologia. Tradução de José Carlos Libâneo e Raquel A. M. da Madeira Freitas, 1988. Disponível em: http://professor.pucgoias.edu.br/SiteDocente/admin/ arquivosUpload/5146/material/DAVYDOV\%20TR ADU\%C3\%87\%C3\%830\%20PROBLEMS\%20OF \%20DEVELOPMENTAL\%20TEACHING\%20(Liv ro).doc Acesso em: 20 nov. 2016.

DE CARLO, M. M. R. do P. Se essa casa fosse nossa: instituições e processos de imaginação na educação especial. 2. ed. São Paulo: Plexus Editora, 2001.

DEPRESBITERIS, L. Instrumentos de avaliação: reflexões sobre seu significado. In: MELO, M.M. 
(org.) Avaliação na Educação. Pinhais - PR:

Editora Melo, 2007. p.95-102.

DUARTE, M. Síndrome de Down: situação escolar no ensino fundamental e médio da cidade de Araraquara-SP. 2008. 179f. Tese (Doutorado em Educação Escolar) - Universidade Estadual Paulista, Faculdade de Ciências e Letras de Araraquara, 2008. . Disponível em: http://hdl.handle.net/11449/101608. Acesso em: 21 fev. 2017.

FERREIRA, M.C.C. A prática educativa e a concepção de desenvolvimento psicológico de alunos com deficiência mental. Campinas, 1994, p. 160. Tese (Doutorado em Educação) - Faculdade de Educação - Universidade Estadual de Campinas, 1994.

GUEBERT, M. C. C. Alfabetização de alunos com deficiência intelectual: um estudo sobre estratégias de ensino utilizadas no ensino regular.

2013.121f.Tese (Doutorado em Educação) Pontifícia Universidade Católica de São Paulo, São Paulo, 2013. Disponível em:

https://tede2.pucsp.br/handle/handle/10392. Acesso em: 30 ag. 2016.

INEP/MEC. Censo escolar da educação básica 2016: notas Estatísticas. Brasília. DF: INEP/MEC, 2017. Disponível em:

http://download.inep.gov.br/educacao_basica/censo _escolar/notas_estatisticas/2017/notas_estatisticas_c enso_escolar_da_educacao_basica_2016.pdf.

Acesso em: 08 jun. 2017

KASSAR, M.C.M. Ciência e senso-comum no cotidiano das classes especiais. 1. ed. Campinas: Papirus, 1995.

MESQUITA, G. O processo de alfabetização de uma criança com deficiência intelectual no $1^{\circ}$ ano do ensino fundamental. 2015. 154f. Dissertação (Mestrado em Educação) - Universidade Federal do Espírito Santo, Centro de Educação, 2015.

Disponível em: http://portais4.ufes.br/posgrad/teses/tese_8849_Diss erta\%E7\%E3o\%20doc.pdf. Acesso em: 14 de set. 2016.

LURIA, A. R. O desenvolvimento da escrita na criança. In: VYGOTSKY, L. S. Linguagem, Desenvolvimento e Aprendizagem. 4. ed. São Paulo:
Ícone/Edusp, 1992.

MARTINS, L. M. O desenvolvimento do psiquismo e a educação escolar: contribuições à luz da psicologia histórico-cultural e da pedagogia histórico-crítica. 1. ed. Campinas: Autores Associados, 2015.

OLIVEIRA, A. A. S. Notas sobre a apropriação da escrita por crianças com Síndrome de Down. Cadernos de Educação, FaE/PPGE/UFPel, Pelotas, v. 36, 337 - 359, maio/agosto 2010.

OLIVEIRA, A. A. S. de. Aprendizagem de alunos com deficiência intelectual do ciclo I do ensino fundamental: o desempenho em leitura e escrita e a formação de professores. In: Leitura: Teoria \& Prática / Associação de Leitura do Brasil. Campinas, SP: Global, 2012. pp. 1796-1805.

PAIXÃO, K. M. G. Mediação pedagógica e deficiência intelectual: em cena a linguagem escrita. 2018. 198f. Tese (Doutorado em Educação) - Universidade Estadual Paulista "Júlio de Mesquita Filho", Faculdade de Filosofia e Ciências, 2018. Disponível em:https://repositorio.unesp.br/bitstream/handle/114 49/153388/paixao_kmg_dr_mar.pdf?sequence=3

PLETSCH, Márcia Denise. Repensando a inclusão escolar: diretrizes políticas, práticas curriculares $e$ deficiência intelectual. Rio de Janeiro:

NAU/EDUR, 2010.

PRESTES, Z. Quando não é quase a mesma coisa: análise de traduções de Lev Semionovitch Vigotski no Brasil - repercussões no campo educacional. 2010.295f. Tese (Doutorado em Educação) Universidade de Brasília, Faculdade de Educação, Brasília, 2010.

SÃO PAULO (município). Secretaria Municipal de Educação. Diretoria de Orientação Técnica. Referencial sobre Avaliação da Aprendizagem na área da Deficiência Intelectual. Secretaria Municipal de Educação - São Paulo: SME / DOT, 2008.

SILVA, L. S. R. G. da. Inclusão: análise das práticas pedagógicas do ciclo alfabetização do ensino fundamental de escolas municipais de Limeira - SP. 2015. 127f. Dissertação (Mestrado em Educação) - Universidade Estadual Paulista, 
Instituto de Biociências de Rio Claro, 2015.

Disponível em: http://hdl.handle.net/11449/134079.

Acesso em: 14 set. 2016.

SIRGADO, A. P. O Conceito de mediação semiótica em Vygotsky e seu papel na explicação do psiquismo humano. In: Caderno CEDES, Campinas, n.24, p.32-44, 1991. [Pensamento e linguagem: estudos na perspectiva da psicologia soviética]

SZYMANSKI, M.L.S.; PELLIZZETTI, I.G.;

IACONO, J.P. O dilema de avaliar o conhecimento na escola: a trajetória de um aluno com déficit intelectual. In: MANZINI, E.J.; MARQUEZINE, M.C.; BUSTOR.M.; TANAKA, E.D.O; FUJISAWA. D.S. Procedimentos de Ensino e Avaliação em Educação Especial. Londrina - PR: ABPEE, 2009.

VALENTIM, F. O. D. (2011). Inclusão de estudantes com deficiência intelectual:

Considerações sobre avaliação da aprendizagem escolar. 2011. 143f. Dissertação (Mestrado em Educação). Universidade Estadual Paulista "Júlio de Mesquita Filho", Faculdade de Filosofia e Ciências,
2011. Disponível em:

https://repositorio.unesp.br/handle/11449/91198.

Acesso em: 03 mar. 2014.

VIGOTSKI, L.S. A construção do pensamento e da linguagem. 2. ed. São Paulo: Editora WMF Martins Fontes, 2009.

. A formação social da mente: o

desenvolvimento dos processos psíquicos superiores. 6. ed. São Paulo: Martins Fontes, 1998.

. Obras Escogidas I. Madrid: Visor

Distribuciones, 1991.

. Obras Escogidas III: incluye problemas del desarrollo de la psique. Madrid: Visor Distribuciones, 1995.

. Obras Escogidas V: fundamentos da defectologia. Madrid: Visor Distribuiciones, 1997.

VYGOTSKY, L. S.; LURIA, A. R. Estudos sobre a história do comportamento: o macaco, o primitivo e a criança. 1. ed. Porto Alegre: Artes Médicas, 1996.

\section{Sobre as autoras}

Katia de Moura Graça Paixão é Doutora em Educação pela Universidade Estadual "Júlio de Mesquita Filho", Pedagoga - Educação Especial, no Colégio de Aplicação da Universidade Federal de Santa Catarina (UFSC) e membro do Grupo de Estudos e Pesquisas em Inclusão Social (GEPIS-UNESP).

Anna Augusta Sampaio de Oliveira é Professora Livre-Docente do Departamento de Educação Especial e do Programa de Pós-graduação em Educação da Faculdade de Filosofia e Ciências "Júlio de Mesquita Filho"e Líder do Grupo de Estudos e Pesquisas em Inclusão Social (GEPIS-UNESP).

Recebido em julho de 2018.

Aprovado em outubro de 2018. 